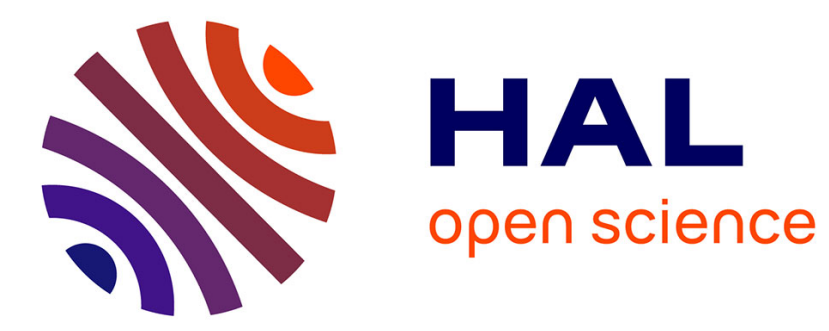

\title{
Modeling the secondary emission yield of salty ice dust grains
}

I. Richterová, Z. Němeček, J. Pavlu, M. Beránek, J. Šafránková

\section{To cite this version:}

I. Richterová, Z. Němeček, J. Pavlu, M. Beránek, J. Šafránková. Modeling the secondary emission yield of salty ice dust grains. Icarus, 2011, 212 (1), pp.367. 10.1016/j.icarus.2010.12.027 . hal-00725408

\section{HAL Id: hal-00725408 \\ https://hal.science/hal-00725408}

Submitted on 26 Aug 2012

HAL is a multi-disciplinary open access archive for the deposit and dissemination of scientific research documents, whether they are published or not. The documents may come from teaching and research institutions in France or abroad, or from public or private research centers.
L'archive ouverte pluridisciplinaire HAL, est destinée au dépôt et à la diffusion de documents scientifiques de niveau recherche, publiés ou non, émanant des établissements d'enseignement et de recherche français ou étrangers, des laboratoires publics ou privés. 


\section{Accepted Manuscript}

Modeling the secondary emission yield of salty ice dust grains

I. Richterová, Z. Němeček, J. Pavlu, M. Beránek, J. Šafránková

PII:

S0019-1035(10)00495-1

DOI:

10.1016/j.icarus.2010.12.027

Reference:

YICAR 9678

To appear in: $\quad$ Icarus

Received Date: $\quad 25$ August 2010

Revised Date: $\quad 25$ November 2010

Accepted Date: $\quad 27$ December 2010

Please cite this article as: Richterová, I., Němeček, Z., Pavlu, J., Beránek, M., Šafránková, J., Modeling the secondary emission yield of salty ice dust grains, Icarus (2010), doi: 10.1016/j.icarus.2010.12.027

This is a PDF file of an unedited manuscript that has been accepted for publication. As a service to our customers we are providing this early version of the manuscript. The manuscript will undergo copyediting, typesetting, and review of the resulting proof before it is published in its final form. Please note that during the production process errors may be discovered which could affect the content, and all legal disclaimers that apply to the journal pertain. 


\title{
Modeling the secondary emission yield of salty ice dust grains
}

\author{
I. Richterová, Z. Němeček, J. Pavlư*, M. Beránek, J. Šafránková \\ Charles University, Faculty of Mathematics and Physics, Department of Surface and \\ Plasma Science, \\ V Holešovičkách 2, 18000 Prague, Czech Republic
}

\section{Abstract}

Secondary emission is one of important processes leading to dust grain charging in many plasma environments. The secondary yield varies with the grain material, shape, and size. Several experiments confirmed that the yield of small grains differs from that of planar samples. Among other materials, ices of different compositions can be frequently found in the interplanetary space and/or planetary magnetospheres. However, the admixtures can significantly influence the inner structure of such materials and thus may change their yield. We present numerical simulations that provide a realistic description of the secondary emission process from water ice grains. The simulations reveal that the secondary emission yield increases as the grain dimension decreases to tens of nanometers. The yield of backscattered primary electrons approaches unity and the grain can be charged to high positive potentials under these conditions. We found that any reasonable admixture of $\mathrm{NaCl}$ does not alter secondary electron emission properties significantly.

\footnotetext{
*Corresponding author.

Email address: jiri.pavlu@mff.cuni.cz (J. Pavlů)
} 
Key words: Secondary electron emission, dust charging, water ice grain, salty ice dust.

\section{Introduction}

In the solar system, vapor-deposited water ice in the amorphous or cubic phases is the principal constituent of the surface of many satellites and rings (Schmitt et al., 1998). Water coexists with other condensed gases and is mixed with mineral grains. The ice surface is a subject to bombardment by energetic particles and UV radiation from the Sun, planetary magnetospheric ions, cosmic rays, and meteorites. These energetic impacts induce many effects on the ice surface, like chemical reactions, electrostatic charging, lattice damage, desorption, and evaporation, some of which alter the surface properties (Johnson, 1998).

Many new results concerning composition and charging properties of dust grains in the solar system and near the planets were discovered by the Cassini mission. The Cosmic Dust Analyser (CDA) provides information about speed, mass, direction, and chemical composition of impacting dust grains (Srama et al., 2004). To determine the chemical composition of particles, a comprehensive statistical analysis of the data sets was performed and the results imply that the vast majority $(>95 \%)$ of the observed particles originate from the Jupiter active volcanic satellite Io. Sodium chloride $(\mathrm{NaCl})$ was identified as a significant particle constituent accompanied by sulphur and potassium. $\mathrm{Na}_{2} \mathrm{SO}_{4}$ and $\mathrm{K}_{2} \mathrm{SO}_{4}$ are minor constituents, each representing 5-10\% of the observed $\mathrm{NaCl}$ mass (Postberg et al., 2006).

CDA measured also the mass spectra in the Saturn's E-ring (e.g., Post- 
berg et al., 2008). An initial interpretation of the data shows that the population of this outermost tenuous E-ring is dominated by tiny water ice particles, some of which contain organic or mineral impurities (e.g., silicates, carbon dioxide, ammonia, molecular nitrogen, hydrocarbons and perhaps carbon monoxide - according to Hillier et al., 2007). The determination of grain size distribution from CDA measurements is difficult, however, the data suggest a significant portion of grains below $0.5 \mu \mathrm{m}$ (Kempf et al., 2008). Optical observations revealed that the water ice grains that are predominantly 0.3 to $3 \mu \mathrm{m}$ in size (Hansen et al., 2006) extend from about three to at least eight Saturn radii, with a peak density at the Enceladus orbit (Showalter et al., 1991).

Active volcanism on Enceladus emits plumes of water vapor and water ice grains from fractures near its south pole (e.g., Hansen et al., 2006; Spahn et al., 2006; Waite Jr. et al., 2006) and these particles are the dominant source of the Saturn's E-ring (Schmidt et al., 2008; Kempf et al., 2008). Recently, Postberg et al. (2009) reported a population of E-ring grains that are rich in sodium salts (approximately to $0.5-2 \%$ of mass). The authors suggested that the Na-rich grains are directly frozen submicrometer droplets and they presented spectra of E-ring particles with different $\mathrm{Na} / \mathrm{H}_{2} \mathrm{O}$ ratios. Their results were confirmed by the experiment where mass spectra of water aggregates generated from a laser-dispersed liquid solution with different sodium salt concentrations were recorded (Charvat and Abel, 2007).

However, having different salt concentration, ice dust grains can accumulate different charges from the surrounding plasma environment. The charging of $1 \mu \mathrm{m}$ spherical water ice grains in the plasma environment in dif- 
ferent parts of the Saturnian E-ring was analytically modeled by Jurac et al. (1995). The authors have shown that the grain surface potential is predominantly determined by the secondary emission and varies from $-5 \mathrm{~V}$ at $4 R_{S}$ (Saturnian radii) to $+5 \mathrm{~V}$ at distances exceeding $8 R_{S}$. The authors stress out the importance of the backscattered (reflected) primary electrons that dominate the charging process especially at the outer parts of the E-ring.

The calculations of Jurac et al. (1995) are based on present knowledge of the secondary electron emission but they cannot properly describe the charging of small (tens/hundreds of nm) grains as well as a possible influence of the salt admixture to the grain charging. With motivation to contribute to these investigations, we have applied a corrected version (Richterová et al., 2010) of the dust grain charging model (Richterová et al., 2006, 2007) and studied the changes of the secondary emission yield of micron and sub-micron spherical grains from water ice caused by gradually increasing salt admixtures. We present results of calculation of the yields of true as well as backscattered electrons from ice grains of sizes ranging from $50 \mathrm{~nm}$ to $10 \mu \mathrm{m}$. A comparison of calculations for a planar ice surface with the experimental data is shown and further used for a model adjustment. The results reveal that the effect of the salt admixture is small even for saturated solution.

\section{The model of SEE from spherical grains}

Secondary electron emission (SEE) plays a prominent role when a portion of energetic $(>10 \mathrm{eV})$ electrons is present in the medium surrounding the grain. The SEE contributes to charging of the spacecraft surface (e.g., Němeček et al., 1997) as well as to charging of dust grains exposed to cos- 
mic radiation (e.g., Weingartner and Jordan, 2008). Many other examples of importance of SEE in space processes can be found in Mann et al. (2004, 2007).

Theoretical assessments of SEE have been based on the elementary theories of Salow (1940a,b); Baroody (1950); Bruining (1954). One of the first complex studies (Sternglass, 1957) describes the SEE from planar metal surfaces in the range from hundreds of electronvolts to a few kiloelectronvolts. Primary electrons impacting the surface interact with the bulk material and lose their energy in many types of collisions what often result in excitations of material electrons and some of the excited electrons can leave the surface. These electrons, the so-called true secondary electrons, have typical energies of a few electronvolts.

For large planar samples, the energy dependence of the SEE yield, $\delta(E)$ (defined as the mean number of secondary electrons per one primary electron) can be described by the Sternglass universal curve (Sternglass, 1957) where the maximum SEE yield, $\delta_{\max }$, and the corresponding primary electron energy, $E_{\text {max }}$, depend only on the sample material at a given incident angle. During collisions with solids, primary electrons change their direction and may be back-scattered from the material, often without a significant loss of their initial energy. The yield of backscattered electrons, $\eta$, increases with the material density and atomic number. It grows slowly with the beam energy above a few hundred of electronvolts for heavy species whereas a decrease of the yield with the energy was observed for light materials like water (see for example the lower curve in Fig. 1). Thus, the total SEE yield, $\sigma=\delta+\eta$, and $\delta$ vary in a similar way with the primary beam energy. 
In the case of small bodies, the process of SEE is very sensitive to the surface curvature (Draine and Salpeter, 1979). The secondary emission yield increases with an incident angle (Bruining, 1954) because the main interaction region is nearer to the surface and thus the highly curved surface of dust grains leads to a yield enhancement (Draine and Salpeter, 1979; Jurac et al., 1995; Richterová et al., 2007). Another important effect is related to the grain size - when the size becomes comparable to the beam penetration depth, more primary electrons can leave the grain. Decreasing further the grain size, no beam electrons can be captured inside the grain, thus they do not deposit their charge inside the grain. On the other hand, they lose a part of their energy by excitation of secondary electrons. As a consequence, a surface potential of very small grains can reach large positive values (e.g., Pavlů et al., 2008; Beránek et al., 2010).

Secondary electrons charge the dust grain positively; negative potentials can be reached only when the total SEE yield is lower than unity. This is generally the case of low beam energies (tens of electronvolts), and in the kiloelectronvolt range, for grain materials with a specific combination of true and backscattered SEE yields.

During the past several years, an enhanced attention has been directed toward numerical simulations of an electron interaction with solids. This interest arises from the application of scanning electron microscopy (SEM) to the analysis of conductors as well as non- or poorly conducting materials such as polymers, ceramics, biological material, and composites.

In widely used Monte Carlo simulations, two phenomena should be modeled: elastic collisions and energy losses. Scattering by inelastic collisions 
is usually neglected due to a small deflection angle resulting from such events (Drouin et al., 1997) and they are considered to be uniformly distributed along the paths of the electrons. Thus, a continuous slowing-down equation based on the Bethe stopping power expression (Bethe, 1933) usually simulates the energy losses. However, in the low-energy range, this expression must be reevaluated since the number of inelastic events is decreasing (e.g., Hovington et al., 1997b).

For elastic events, the Rutherford theory (Rutherford, 1911) has been widely used due to its simplicity and its short computation time (Joy and Luo, 1989). This model is accurate for a high-energy interaction (> $10 \mathrm{keV})$ but it is not valid for low energies. At the low-energy range, the more accurate Mott theory (Mott and Massey, 1965) is preferable. Empirical forms of the Mott cross section have been developed recently (e.g., Browning et al., 1995). The differential Mott cross sections for each element of the periodic table were computed by Czyżewski et al. (1990).

However, the majority of models were applied to the planar metal or insulating targets but only a few papers dealt with spherical samples. A complex analytical calculation (Jurac et al., 1995) of the charge accumulated by spherical ice grains under Saturnian E-ring conditions involves both true and backscattered (called reflected therein) electrons and the influence of the grain curvature but it is not able to reproduce size effects. The authors limited the validity of their calculations to $1 \mu \mathrm{m}$ of the grain diameter but the Saturnian environment contains significantly smaller grains.

Ziemann et al. (1995) and Chow et al. (1993, 1994) developed different analytical models but none of them match the experimental data when the 
size effect becomes notable. A simple numerical model of secondary emission from small dust grains developed by Richterová et al. (2004) has revealed also the importance of backscattered electrons to the determination of the equilibrium surface potential, especially for high primary energies. The main assumptions of the Richterová et al. (2004) model were that primary electrons inside the grain travel a mean free path (energy dependent), collide with an atom, loss a constant portion of its energy and change the direction of their motion according to cosine law.

Since the model assumptions were very simplified, the authors have revised it in order to include more complex principles of the electron-solid interaction that will be specified bellow. The improved model (Richterová et al., 2006) provides the charge accumulated in the grain as a function of the primary beam energy which is directly measurable as well as the energetic dependence of the secondary and backscattered yields. The new model was successfully verified by laboratory experiments with charging of gold (Richterová et al., 2006) and glass (Richterová et al., 2007) dust grains. However, further investigations revealed a small disagreement of model predictions and experiments for light materials like carbon, thus Richterová et al. (2010) suggested several model corrections. Since the present paper deals with the water ice and the corrections are substantial for this material, we briefly review their approach that is applied to calculations presented in the next section.

The model follows trajectories of primary electrons inside the spherical grain of a given composition. A deflection angle is generated according to energy-dependent Mott differential cross-sections (Mott and Massey, 1965). Note that these cross-sections are calculated in 2D and provide only the total 
deflection angle. Since our model is 3D, we use this angle as a polar angle and generate the azimuthal angle in a random way. In the case of compounds, we do not compute a new weighted differential cross-section but a random number is generated to decide which of particular species cause the electron deflection at each collision.

Integrating radial cross-section over a whole space angle, we can obtain the total cross-section, $\sigma_{\mathrm{T}}(E)$ where $\sigma_{\mathrm{T}}$ decreases monotonously with the energy and can be well interpolated via cubic splines.

A path length between two subsequent collisions, $\lambda(E)$, is generated according to $\sigma_{\mathrm{T}}(E)$. The energy of primary electrons decreases continuously along its path. Since a corresponding change of $\sigma_{\mathrm{T}}(E)$ between two subsequent collisions can be often neglected, the mean free forceless path, $\lambda(E)$ was used in Richterová et al. (2006, 2007):

$$
\lambda(E)=\left(\sum n_{j} \sigma_{\mathrm{T} j}(E)\right)^{-1}
$$

where $n_{j}$ is a number density of deflecting atoms of $j$-th elemental species.

For a given uniform random number, $\xi$, from the interval $(0,1)$ we can write

$$
\Delta s=-\lambda(E) \ln (\xi)
$$

When the $\sigma_{\mathrm{T}}$ increase along electron path is not omitted, electrons travel a shorter path than that given by a mean free path, $\lambda(E)$ from Eq. (1). In present calculations, the probability $P$ that an electron of the energy $E$ does not undergo any collision decreases with the path length, $\Delta s$ exponentially:

$$
P(E, \Delta s)=\exp (-f(E, \Delta s)) .
$$


The accumulation function, $f(E, \Delta s)$ can be written as:

$$
f(E, \Delta s)=\int_{s(E)}^{s(E)+\Delta s} \sum n_{j} \sigma_{\mathrm{T} j}\left(s^{\prime}\right) d s^{\prime} .
$$

Generation of the path segment between subsequent collisions requires to solve an expression

$$
f(E, \Delta s)=-\ln (\xi)
$$

For calculations of the traveling path of primary electrons, we use modified Bethe stoping power formula (Joy and Luo, 1989):

$$
\frac{\mathrm{d} E}{\mathrm{~d} s} \sim-\frac{\varrho}{N} \frac{A_{\mathrm{eff}}(E)}{E} \ln \frac{1.166 E}{J_{\mathrm{eff}}(E)}
$$

where $E$ is an actual electron energy, $s$ is the traveled path, $\varrho$ is a mass density, and $N$ is the nucleon number. The effective number of atom electrons, $A_{\text {eff }}(E)$ and the effective mean ionization potential, $J_{\text {eff }}(E)$ are calculated using the Hovington et al. (1997a) approach and optical absorbtion data for water and ice (Palik, 1991; Warren and Brandt, 2008).

Integration of Eq. 6 provides the energy of primary electrons as a function of the path traveled inside the grain, $E(s)$, that does not depend on the actual trajectory of a particular electron. Using inverse function, $s(E)$, we can then determine the accumulation function, $f(E, \Delta s)$ and obtain $\Delta s$ for a given $\xi$.

To test the model performance, we have calculated the yields $\delta$ and $\eta$ as a function of the primary beam energy for a planar sample from pure water ice and compared them with available experimental data. Fig. 1 shows a good agreement of modeled and measured profiles. We should point out that the values of $\eta$ follow directly from the model calculation, whereas the $\delta$ values were scaled by fitting of the computed profile to the experimental 
data because the absorbtion length of excited electrons inside the grain, $\Lambda$, is a free parameter of the model. The fit shown in Fig. 1 as a gray line provides a value of $\Lambda=4.5 \mathrm{~nm}$ that is a mean value for the whole energy spectrum of true secondary electrons . Experimentally and theoretically determined values for ice films $(\approx 2$ monolayers for $\approx 1 \mathrm{eV}$ electrons and $\approx 4$ monolayers for $\approx 3 \mathrm{eV}$ electrons (Gilton et al., 1989, experiment); $\approx 2.3$ monolayers for $\approx 3.5 \mathrm{eV}$, i.e., $\approx 0.87 \mathrm{~nm}$ (Jo and White, 1991 , experiment); $\approx 1.3$ monolayers for $1 \mathrm{eV}$ electrons and $\approx 5$ monolayers for $4.7 \mathrm{eV}$ electrons, i.e., $\approx 0.49 \mathrm{~nm}$ and $\approx 1.89 \mathrm{~nm}$, respectively, (Barnett et al., 1990, theory)) show an increase of this length with the energy. Since our fit provides an average value for the whole spectrum of secondary electrons (i.e., in the range of $\approx 0-50 \mathrm{eV}$ ), we believe that our result is in a good agreement with the aforementioned data.

\section{Water ice grain with varying salt content}

The modified model described above was applied on water ice grains of different diameters and salinity. The presented model results are based on following assumptions:

- spherical ice grains (with $\varrho=0.92 \mathrm{~g} \mathrm{~cm}^{-3}$ ) of a given diameter are bombarded by the parallel electron beam;

- $\mathrm{Na}$ and $\mathrm{Cl}$ atoms are distributed uniformly inside the grain, the grain mass density increases in accord with the portion of $\mathrm{NaCl}$;

- free path of excited electrons is not altered by the salt admixture;

- the energetic distribution of the true secondary electrons according 


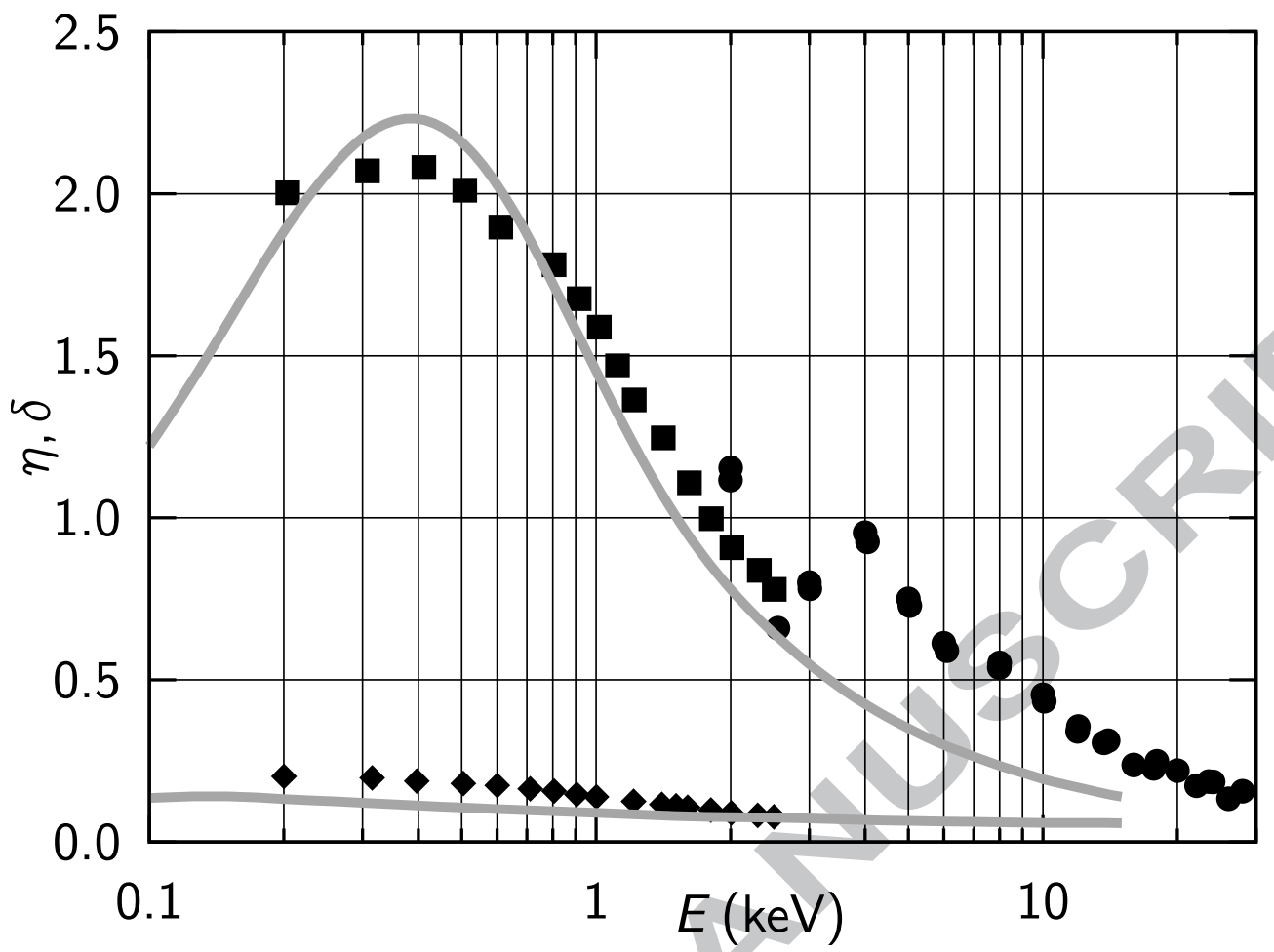

Figure 1: A comparison of modeled profile of the true secondary electron emission yield, $\delta$ (top curve) and backscattered yield, $\eta$ (bottom curve) with experimental data (diamonds $\eta$ according to Matskevich and Mikhailova (1960) for pure water ice; squares $-\delta$ according to Matskevich and Mikhailova (1960); and circles $-\delta$ according to Suszcynsky et al. (1992)).

to Chung and Everhart (1974) with the ice work function of $4.2 \mathrm{eV}$ is used;

- the results for water ice were calibrated to match measurements on planar samples at $77 \mathrm{~K}$ (Matskevich and Mikhailova, 1960).

We are analyzing effects of the grain size and the salt admixtures. For this reason, results are shown in three pairs of figures. Each of them presents the size dependence as modeled for the water ice grains in the (a) panels, 
whereas the influence of the $\mathrm{NaCl}$ admixture is shown for a $300 \mathrm{~nm}$ grain in the (b) panels.

Fig. 2 shows the backscattered yield, $\eta$, as a function of the primary energy. The profile computed for a planar sample is given as a reference in Fig. 2a. The increase of $\eta$ for water ice grains with dimensions equal to (or larger than) $10 \mu \mathrm{m}$ is caused by the surface curvature and is independent on the grain size because it is given by the distribution of incidence angles of the parallel beam along the spherical surface. A further decrease of the grain diameter leads to a rapid increase of $\eta$ towards unity. The energy at which the increase becomes observable decreases, whereas the slope of this rise enhances for small grains. As it can be seen from Fig. 2b, the salt admixture exhibits a similar effect as the increase of the grain diameter but the effect is nearly negligible. The results shown for a $300 \mathrm{~nm}$ grain and $20 \%$ of the salt reveal that this admixture causes an effect similar to increase of the grain diameter by $\approx 2 \%$.

Fig. 3a shows how the yield of true secondary electrons changes with the decreasing grain diameter. Similarly to the $\eta$ profiles in Fig. 2a, the increase of $\delta$ from values calculated for a planar surface to those for the $10 \mu \mathrm{m}$ grain are connected with the curved surface and this effect does not depend on the diameter.

For smaller grains, the maximum of $\delta$ increases and its position shifts toward higher energies. The "bump" on the profile computed for $300 \mathrm{~nm}$ is caused by the fact that a great majority of primary electrons is leaving the grain with a small energy, thus they excite a large number of secondary electrons near the surface. Note that this effect causes $\delta$ being larger for 
the $300 \mathrm{~nm}$ grain than for the $50 \mathrm{~nm}$ grain for energies above $\approx 2 \mathrm{keV}$. On the other hand, the salt admixture (Fig. 3b) increases the secondary electron yield by a small factor that is a rising function of this admixture but that only slightly depends on the primary beam energy.

Combining the above results together and adding the energetic spectrum of true secondary electrons, we can compute the surface potential that a grain acquires. These potentials reached by the grain charging with a parallel beam of primary electrons are plotted in Fig. 4 as a function of their energy for water ice and ice with different salt admixtures. The energetic spectrum and the yield of true secondary electrons influence the grain potential at a low-energy range, whereas the backscattered electrons are responsible for the sharp rise of the potential when $\eta$ approaches unity. We stopped our computations at $25 \mathrm{~V}$ but the limit is close to a half of the beam energy (Reid et al., 2008). This result is very important because the backscattered yield and the energetic spectrum of the back-scattered electrons are modeled without any additional assumption and the rise of the potential is realistic. We can note that a similar rise of the grain potential was recorded by Beránek et al. (2010) in experimental investigations of the JCS-1 Mars soil simulant.

Fig. 4a shows that $10 \mu \mathrm{m}$ grains can reach a potential of about $7.6 \mathrm{~V}$ at $500 \mathrm{eV}$ of the primary energy and that the potential decreases for higher energies being nearly zero at $5 \mathrm{keV}$ because the charge of primary electrons deposited in the grain (about 25\%, Fig. 2a) is compensated by the charge of outgoing true secondary electrons. A decrease of the grain diameter up to $300 \mathrm{~nm}$ does not alter the potential profile at low (below $1 \mathrm{keV}$ ) energies; both $\delta$ and $\eta$ do not change with the grain diameter in this energy range. 
High potentials observed for smaller grains and/or higher primary energies are connected with the sharp rise of $\eta$ (Fig. 2a) as discussed above. Since Fig. $2 \mathrm{~b}$ and Fig. 3b show that the changes of $\delta$ and $\eta$ with the salt admixture are small; the same is true for the grain potential as demonstrated in Fig. 4b.

\section{Discussion}

We have developed a simple model of SEE that well describes and follows trajectories of primary electrons, and thus it gives a reliable number of scattered electrons. The conversion of the deposited energy to emitted true secondary electrons is treated only statistically through the mean transferred energy and the attenuation length of exited electrons (e.g., Lin and Joy, 2005). We successfully applied this approach to modeling of charging of another insulating compound-glass grains (Richterová et al., 2007).

Other possibility is to follow particular products of each inelastic collision (Schreiber and Fitting, 2002; Kieft and Bosch, 2008). Corresponding scattering cross-sections can be derived using optical data for dispersion relations (including the acoustic deformation potential and longitudinal optical phonos properties for insulators). However, a lack of input data and approximate relations would cause large errors in determination of electron cascades for complex materials.

Taking into account these constrains, we believe that our approach provides more reliable results. Our calculations assume that $\mathrm{Na}$ and $\mathrm{Cl}$ atoms are distributed uniformly inside the grain for the purpose of the scattering of the primary beam, whereas the emission of true secondary electrons is adjusted to data measured on a pure water ice (Fig. 1). These two as- 
sumptions are apparently contradictory. However, the theory of Onsager and Samaras (1934) demonstrates that the dissolved ions are repulsed from the water surface by electrostatic image forces. These results were confirmed for light species by molecular dynamics calculations (Vrbka and Jungwirth, 2005). Their calculations reveal that we can expect several atomic layers of pure water at the grain surface in liquid phase and, because the freezing is rapid (Postberg et al., 2009), the same would be true for icy grains. The emission of true secondary electrons is governed by the surface properties that are given by composition of several uppermost atomic layers, thus our simplification is substantiated. On the other hand, the scattering of primary electrons proceeds in the whole volume of small grains. The first collision occurs in a depth where $\mathrm{Na}$ and $\mathrm{Cl}$ atoms are already uniformly distributed, thus our omission of several atomic layers at the grain surface cannot spoil the results.

The potential of water ice dust grains in the Saturnian E ring was modeled by Jurac et al. (1995). The authors used available experimental data on the secondary emission yield from planar samples and the angular dependence of the yield and compute the secondary emission yield from a sphere. They obtained the increase of $\delta$ by a factor of $\approx 1.5$; slightly larger than that following from our model $(\approx 1.2$, see Fig. 3a). This difference is small and it is connected with the angular dependence of $\delta$. Jurac et al. (1995) used the experimental data that hold for heavier species but the smaller deflection of primary electrons in collisions with light elements leads to a little different result. Larger values of $\delta$ compensate the omission of the increase of the yield of backscattered electrons (Fig. 2a) due to grain surface curvature. Conse- 
quently, they obtained the same $\sigma$ but slightly smaller positive equilibrium potentials than our results. Nevertheless, we show that Jurac et al. (1995) calculations can be used without notable corrections for the grain diameter exceeding $\approx 1 \mu \mathrm{m}$, whereas smaller grains would charge to larger positive potentials. On the other hand, the presence of the salt in the water-ice grains does not alter their potential substantially.

\section{Conclusion}

Our simulations of the secondary electron emission yield of water ice grains show that the yield is greater than unity from $\approx 30 \mathrm{eV}$ to several keV. Thus, these grains can achieve a negative equilibrium potential only if the Saturn E-ring plasma is cold enough (i.e., the secondary electron emission does not contribute significantly to the charging current) and the contribution of photoemission would be negligible.

Furthermore, the calculations reveal that any reasonable admixture of $\mathrm{NaCl}$ does not change the secondary emission properties of small icy dust grains of a given diameter. We would like to note that from our discussion of a probable grain structure it follows that the same conclusions would be valid for the photoemission because the emission of electrons excited by energetic photons proceeds by the same way as the emission of true secondary electrons.

\section{Acknowledgements}

This work was supported partly by the Research plan MSM 0021620860 financed by the Ministry of Education of the Czech Republic, partly by the Czech Grant Agency under Contracts 202/08/0063, 202/08/P066, and 
202/08/H057. M. Beránek thanks for a support by the Grant Agency of Charles University.

\section{References}

Barnett, R.N., Landman, U., Nitzan, A., 1990. Primary events following electron injection into water and adsorbed water layers. J. Chem. Phys. $93,6535-6542$.

Baroody, E.M., 1950. A Theory of Secondary Electron Emission from Metals. Phys. Rev. 78, 780-787.

Beránek, M., Pavlů, J., Vaverka, J., Richterová, I., Šafránková, J., Němeček, Z., 2010. Properties of martian soil simulant. J. Geophys. Res. to be submitted.

Bethe, H.A., 1933. Handbook of Physics. volume 24. Springer, Berlin.

Browning, R., Li, T.Z., Chui, B., Jun, Y., Pease, R.F.W., Czyzewski, Z., Joy, D.C., 1995. Low energy electron/atom elastic scattering cross section from $0.1-30$ kev. Scanning 17, 250-253.

Bruining, H., 1954. Physics and Applications of Secondary Emission. Pergamon, London.

Charvat, A., Abel, B., 2007. How to make big molecules fly out of liquid water: applications, features and physics of laser assisted liquid phase dispersion mass spectrometry. Phys. Chem. Chem. Phys. 9, 3335-3360. 
Chow, V., Mendis, D., Rosenberg, M., 1993. Role of grain size and particle velocity distribution in secondary electron emission in space plasmas. J. Geophys. Res. 98, 19065-19076.

Chow, V., Mendis, D., Rosenberg, M., 1994. Secondary emission from small dust grains at high electron energies. IEEE Trans. Plasma Sci. 22, 179-186.

Chung, M.S., Everhart, T.E., 1974. Simple calculation of energy distribution of low-energy secondary electrons emitted from metals under electron bombardment. J. Appl. Phys. 45, 707-709.

Czyżewski, Z., O’Neill MacCallum, D., Romig, A., Joy, D.C., 1990. Calculations of Mott scattering cross sections. J. Appl. Phys. 68, 3066-3072.

Draine, B., Salpeter, E., 1979. On the physics of dust grains in hot gas. Astrophys. J. 231, 77-94.

Drouin, D., Hovington, P., Gauvin, R., 1997. CASINO: A New Monte Carlo Code in C Language for Electron Beam Interaction. 2. tabulated values of the Mott cross section. Scanning 19, 20-28.

Gilton, T.L., Dehnbostel, C.P., Cowin, J.P., 1989. Electron transmission through layers of $\mathrm{H}_{2} \mathrm{O}$ and $\mathrm{Xe}$ in the ultrahigh vacuum photoreduction of $\mathrm{CH}_{3} \mathrm{Cl}$ on $\mathrm{Ni}(111)$. J. Chem. Phys. 91, 1937-1938.

Hansen, C.J., Esposito, L., Stewart, A.I.F., Colwell, J., Hendrix, A., Pryor, W., Shemansky, D., Wast, R., 2006. Enceladus' water vapor plume. Science $311,1422-1425$. 
Hillier, J.K., Green, S.F., McBride, N., Schwanethal, J.P., Postberg, F., Srama, R., Kempf, S., Moragas-Klostermeyer, G., McDonnell, J.A.M., Grün, E., 2007. The composition of Saturn's E ring. Mon. Not. R. Astron. Soc. $377,1588-1596$.

Hovington, P., Drouin, D., Gauvin, R., 1997a. CASINO: A New Monte Carlo Code in C Language for Electron Beam Interaction. 1. description of the program. Scanning 19, 1-14.

Hovington, P., Drouin, D., Gauvin, R., Joy, D.C., Evans, N., 1997b. CASINO: A New Monte Carlo Code in C Language for Electron Beam Interaction. 3. stopping power at low energies. Scanning 19, 29-35.

Jo, S.K., White, J.M., 1991. Low energy $(<1 \mathrm{eV})$ electron transmission through condensed layers of water. J. Chem. Phys. 94, 5761-5764.

Johnson, R.E., 1998. Sputtering and Desorption from Icy Surfaces, in: Schmitt, B., De Bergh, C., Festou, M. (Eds.), Solar System Ices, Kluwer, Dordrecht. pp. 303-336.

Joy, D.C., Luo, S., 1989. An empirical stopping power expression for low energy electrons. Scanning 11, 176-180.

Jurac, S., Baragiola, R.A., Johnson, R.E., Sittler, E.C., 1995. Charging of ice grains by low-energy plasmas: Application to Saturn's E ring. J. Geophys. Res. 100, 14821-14832.

Kempf, S., Beckmann, U., Moragas-Klostermeyer, G., Postberg, F., Srama, R., Economou, T., Schmidt, J., Spahn, F., Grün, E., 2008. The E ring in 
the vicinity of Enceladus. I. spatial distribution and properties of the ring particles. Icarus 193, 420-437.

Kieft, E., Bosch, E., 2008. Refinement of Monte Carlo simulations of electron specimen interaction in low-voltage SEM. J. Phys. D 41, 215310.

Lin, Y., Joy, D.C., 2005. A new examination of secondary electron yield data. Surf. Interface Anal. 37, 895-900.

Mann, I., Kimura, H., Biesecker, D.A., Tsurutani, B.T., Grün, E., McKibben, R.B., Liou, J.C., MacQueen, R.M., Mukai, T., Guhathakurta, M., Lamy, P., 2004. Dust near the Sun. Space Sci. Rev. 110, 269-305.

Mann, I., Murad, E., Czechowski, A., 2007. Nanoparticles in the inner solar system. Planet. Space. Sci. 55, 1000-1009.

Matskevich, T.L., Mikhailova, E.G., 1960. Secondary electron emission in ice and anthracene films. Solid State Phys. 2, 709-715.

Mott, N., Massey, H., 1965. Theory of atomic collisions. Oxford University Press, New York.

Němeček, Z., Šafránková, J., Přech, L., Šimůnek, J., Šmilauer, J., Gringauz, K., Shutte, N., Teltsov, M., Marjin, B., Ruzhin, Y., Dokukin, V., 1997. Artificial electron and ion beam effects: Active plasma experiment. J. Geophys. Res. 102, 2201-2211.

Onsager, L., Samaras, N.N.T., 1934. The Surface Tension of Debye-Hückel Electrolytes. J. Chem. Phys. 2, 528-536. 
Palik, E.D., 1991. Handbook of optical constants of solids II. Academic Press, Boston.

Pavlů, J., Richterová, I., Němeček, Z., Šafránková, J., Čermák, I., 2008. Interaction between single dust grains and ions or electrons: laboratory measurements and their consequences for the dust dynamics. Faraday Discuss. 137, 139-155.

Postberg, F., Kempf, S., Hillier, J.K., Srama, R., Green, S.F., McBride, N., Grün, E., 2008. The E-ring in the vicinity of Enceladus: II. probing the moon's interior — the composition of E-ring particles. Icarus 193, 438-454.

Postberg, F., Kempf, S., Schmidt, J., Brilliantov, N., Beinsen, A., Abel, B., Buck, U., Srama, R., 2009. Sodium salts in E-ring ice grains from an ocean below the surface of Enceladus. Nature 459, 1098-1101.

Postberg, F., Kempf, S., Srama, R., Green, S.F., Hillier, J.K., McBride, N., Grün, E., 2006. Composition of jovian dust stream particles. Icarus 183, $122-134$.

Reid, J.P., Shiratani, M., Goree, J.A., Rühl, E., Kersten, H., Stoffels, W.W., Pavli̊, J., Signorell, R., Davidovits, P., Rudich, Y., Mason, N., Ray, A., Chang, R.K., Kahan, T., King, M.D., Ammann, M., McGloin, D., Jaenicke, R., 2008. General discussion. Faraday Discuss. 137, 193-204.

Richterová, I., Beránek, M., Pavlů, J., Němeček, Z., Šafránková, J., 2010. Electrons scattered inside small dust grains of various materials. Phys. Rev. B 81, 075406. 
Richterová, I., Němeček, Z., Šafránková, J., Pavlů, J., 2004. A model of secondary emission from dust grains and its comparison with experiment. IEEE Trans. Plasma Sci. 32, 617-622.

Richterová, I., Němeček, Z., Šafránková, J., Pavli̊, J., Beránek, M., 2007. Secondary emission from glass grains: Comparison of the model and experiment. IEEE Trans. Plasma Sci. 35, 286-291.

Richterová, I., Pavlů, J., Němeček, Z., Šafránková, J., 2006. Model of secondary emission and its application on the charging of gold dust grains. Phys. Rev. B 74, 235430.

Rutherford, E., 1911. The scattering of $\alpha$ and $\beta$ particles by matter and the structure of the atom. Philos. Mag. 21, 669-688.

Salow, H., 1940a. Angular dependence of the secondary electron emission from insulators. Phys. Z. 41, 434. In German.

Salow, H., 1940b. On the secondary electron yield of electron bombarded insulators. Z. Techn. Phys. 21, 8-15. In German.

Schmidt, J., Brilliantov, N., Spahn, F., Kempf, S., 2008. Slow dust in Enceladus' plume from condensation and wall collisions in tiger stripe fractures. Nature 451, 685-688.

Schmitt, B., De Bergh, C., Festou, M. (Eds.), 1998. Solar System Ices. volume 227 of Astrophysics and Space Science Library, Kluwer, Dordrecht.

Schreiber, E., Fitting, H.J., 2002. Monte Carlo simulation of secondary 
electron emission from the insulator $\mathrm{SiO}_{2}$. J. Electron Spectrosc. Relat. Phenom. 124, 25-37.

Showalter, M.R., N. Cuzzi, J., Larson, S.M., 1991. Structure and particle properties of Saturn's E ring. Icarus 94, 451-473.

Spahn, F., Schmidt, J., Albers, N., Hörning, M., Makuch, M., Seiß, M.,

Kempf, S., Srama, R., Dikarev, V., Helfert, S., Moragas-Klostermeyer, G., Krivov, A.V., Sremčević, M., Tuzzolino, A.J., Economou, T., Grün, E., 2006. Cassini dust measurement at Enceladus and implications for the origin of the E ring. Science 311, 1416-1418.

Srama, R., Ahrens, T., Altobelli, N., Auer, S., Bradley, J., et al., 2004. The Cassini Cosmic Dust Analyzer. Space Sci. Rev. 114, 465-518.

Sternglass, E., 1957. Theory of Secondary Electron Emission under Electron Bombardment. Scientific Paper 6-94410-2-P9. Westinghouse Research Laboratories. Pittsburgh 35.

Suszcynsky, D.M., Boroysky, J.E., Goertz, C.K., 1992. Secondary electron yields of solar system ices. J. Geophys. Res. 97, 2611-2619.

Vrbka, L., Jungwirth, P., 2005. Brine Rejection from Freezing Salt Solutions: A Molecular Dynamics Study. Phys. Rev. Lett. 95, 148501.

Waite Jr., J.H., Combi, M.R., Ip, W.H., Cravens, T.E., McNutt Jr., R.L., Kasprzak, W., Yelle, R., Luhmann, J., Niemann, H., Gell, D., Magee, B., Fletcher, G., Lunine, J., Tseng, W.L., 2006. Cassini ion and neutral mass spectrometer: Enceladus plume composition and structure. Science 311, $1419-1422$. 
Warren, S.G., Brandt, R.E., 2008. Optical constants of ice from the ultraviolet to the microwave: A revised compilation. J. Geophys. Res. 113, 14220.

Weingartner, J.C., Jordan, M.E., 2008. Torques on spheroidal silicate grains exposed to anisotropic interstellar radiation fields. Astrophys. J. 672, 382 390.

Ziemann, P., Liu, P., Kittelson, D., McMurry, P., 1995. Electron impact charging properties of size-selected, submicrometer organic particles. J. Phys. Chem. 99, 5126-5138. 


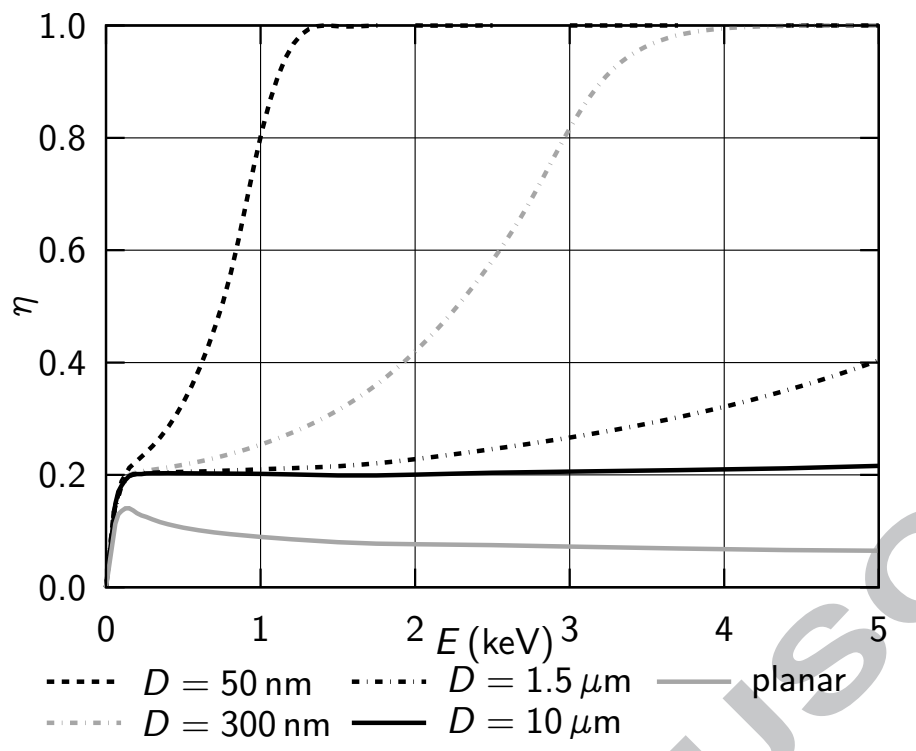

(a)

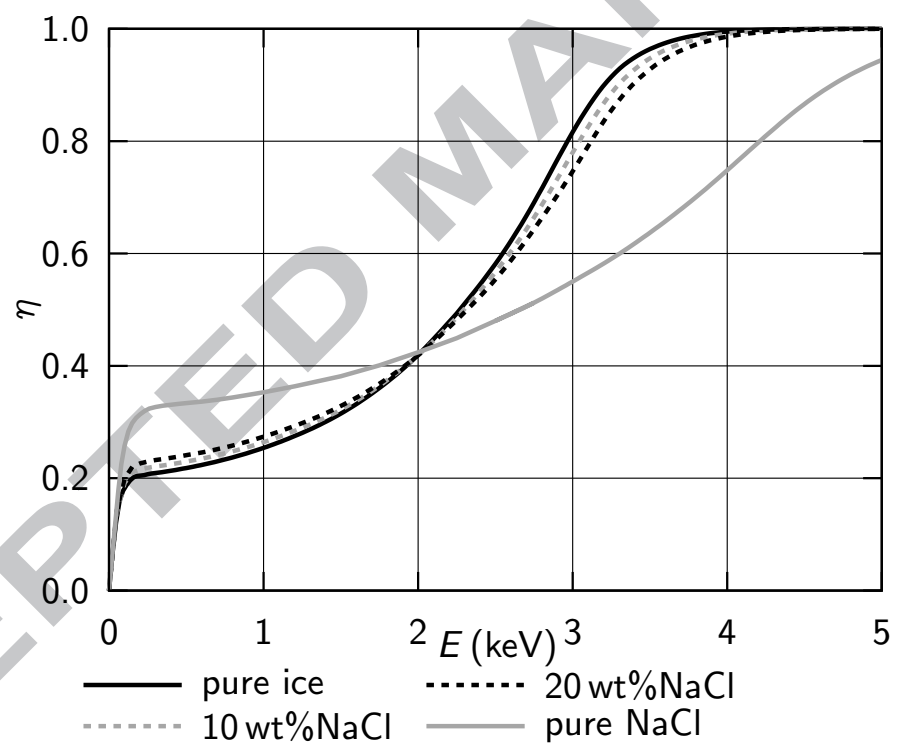

(b)

Figure 2: Modeled backscattered electron yields for water ice grains of different diameters (a) and for a $300 \mathrm{~nm}$ ice grain with different salt admixtures (b). 


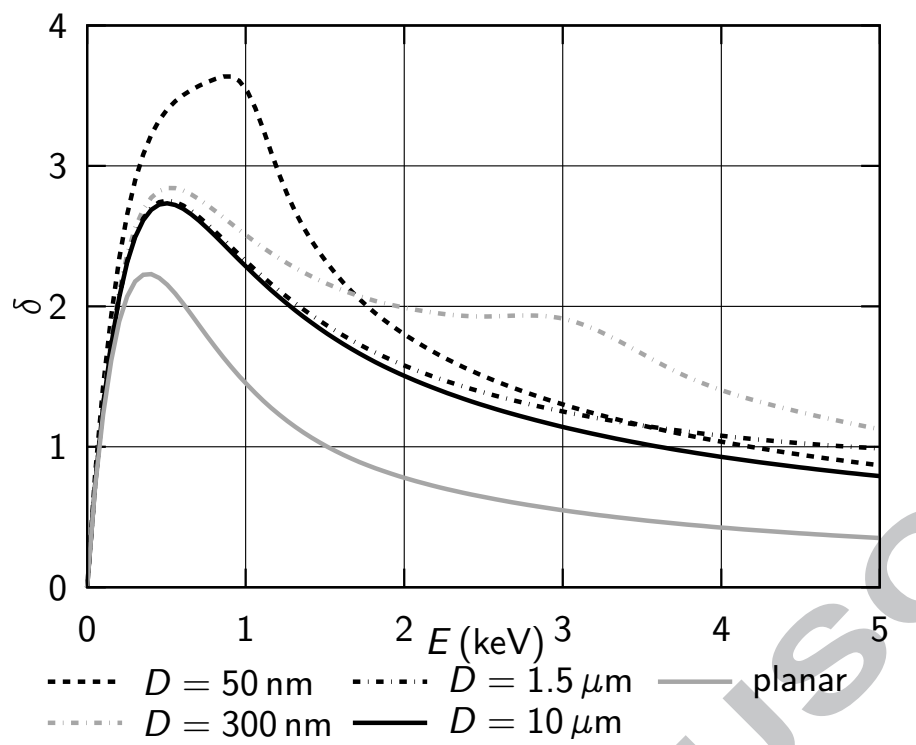

(a)

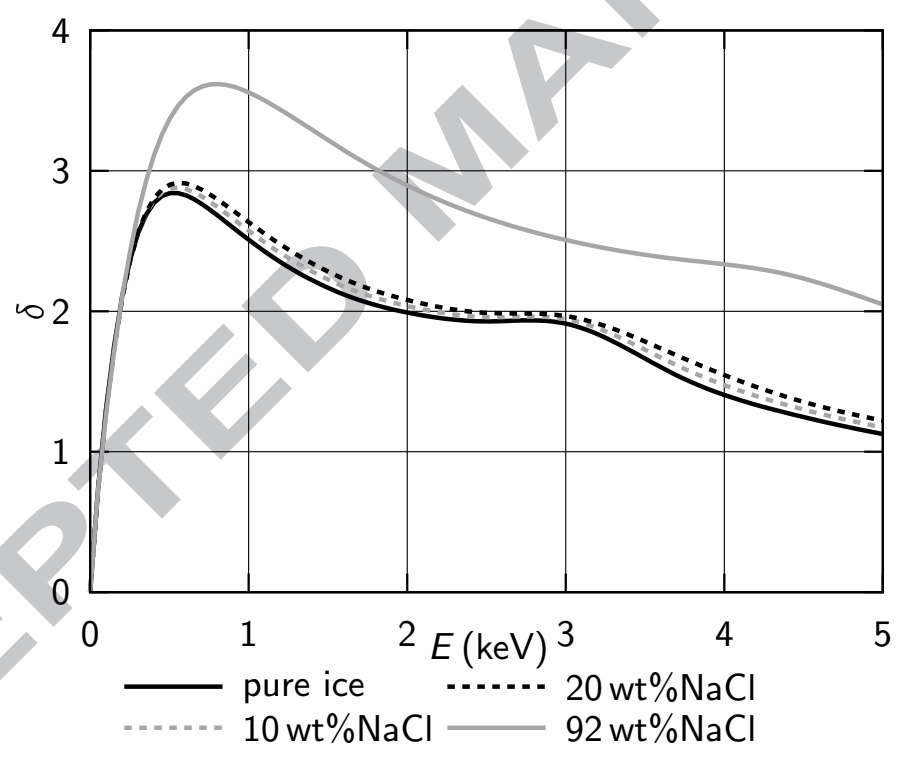

(b)

Figure 3: Modeled true secondary emission yield for water ice grains of different diameters (a) and a $300 \mathrm{~nm}$ ice grain with different salt admixtures (b). 


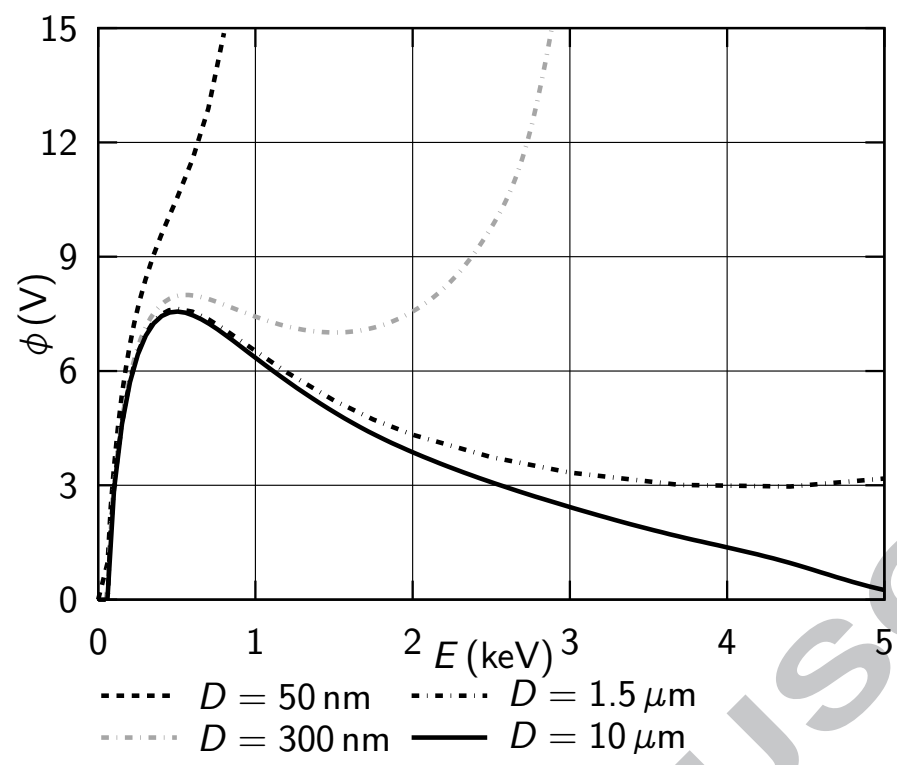

(a)

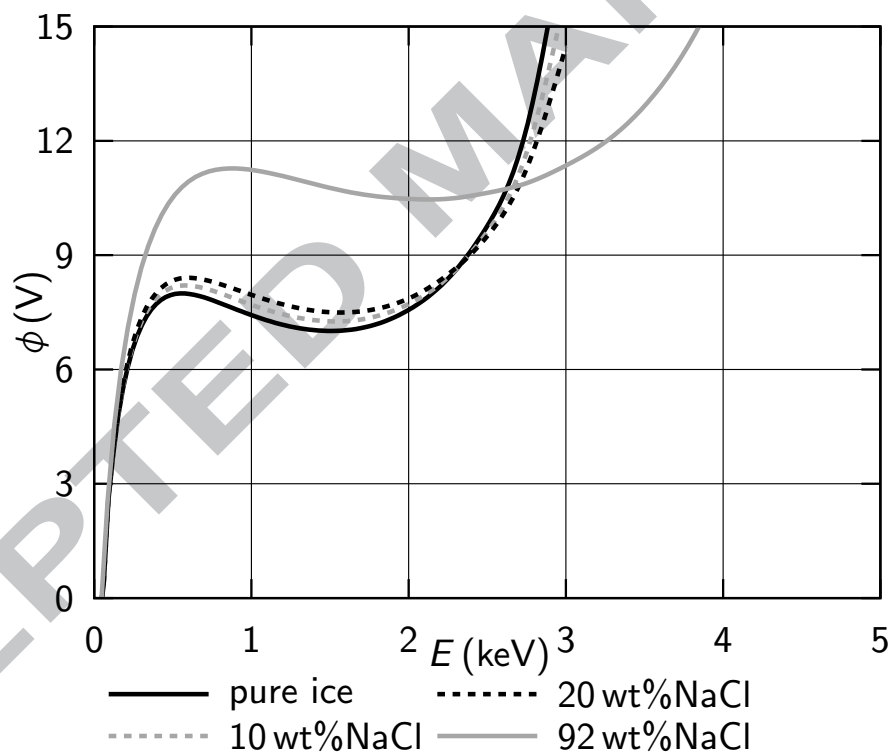

(b)

Figure 4: Computed surface potentials for water ice grains of different diameters (a) and a for $300 \mathrm{~nm}$ ice grain with different salt admixtures (b). 